\title{
Theoretical study on the electronic, optoelectronic, linear and non linear optical properties and UV-Vis Spectrum of Coronene and Coronene substituted with Chlorine
}

\author{
G. W. Ejuh ${ }^{1,2} \cdot$ F. Tchangnwa Nya ${ }^{3} \cdot$ N. Djongyang ${ }^{4}$ J. M. B. Ndjaka ${ }^{5}$
}

Received: 1 April 2020 / Accepted: 9 June 2020 / Published online: 19 June 2020

(c) Springer Nature Switzerland AG 2020

\begin{abstract}
We have study electronic, optoelectronic, linear and nonlinear optical; thermodynamic properties and UV-Vis Spectrum of Coronene and Coronene substituted with Chlorine using time-dependent density functional theory TD-DFT (TDwB97XD, TD-B3LYP, TD-LSDA and TD-CCSD(T)). We quantified the effect of substitution of hydrogen atoms with Chlorine for a series of molecular properties relevant for molecular electronics and photonics. Results obtained with TD-B3LYP and TD-CCSD(T) are closer to experimental results reported in literature for Coronene substituted with Chlorine. Second hyperpolarizability $\left(\gamma_{a v}\right)$ values show that the molecules have very good optoelectronic, linear and non linear optical properties. $E_{\mathrm{g}}$ show that the molecules may have semiconductors properties and hence have applications in photonic, electronic and optoelectronic devices.
\end{abstract}

Keywords TD-DFT · Electronics · Optoelectronics · Photonics · Second molecular hyperpolarizability

\section{Introduction}

Recently, studies have shown that the production and consumption of energy might change if the research in organic electronics can improve on the efficiency and application in optoelectronic materials. Organic molecules have applications in photonic, linear and nonlinear optics, thin-film transistors (TFT), light emitting diodes (OLED) and thin-film photovoltaic cells (OPV). This is because organic molecules are relatively cheap, light and flexible and are in great abundant [1]. Equally, the physical, chemical, mechanical and electronic properties of these molecules can vary by adding specific functional groups at different positions and doping of the molecules with other atoms. Studies have proven that the homologous classes of polycyclic aromatic hydrocarbons in their crystalline state are among the materials which can be used in organic electronics [2]. For instance, oligoacenes and their derivatives, are constantly being used as active elements in various optoelectronic devices like in organic thin-film field-effect transistors [3], light-emitting diodes [4], photovoltaic cells [5], and liquid crystals [6].

Organic electronics based on acenes and heteroacenes is presently an interesting area of research [7-11]. Formation, migration, and dissociation of exciton, charge transport, charge collection at the electrodes, molecular packing in the bulk material, and absorption and emission properties are the main features controlling organic semiconductor devices $[12,13]$. Consequently, a detailed understanding of the electronic structure of the molecular

G. W. Ejuh, gehwilsonejuh@yahoo.fr | ${ }^{1}$ Department of Electrical and Electronic Engineering, National Higher Polytechnic Institute, University of Bamenda, P.O. Box 39, Bambili, Cameroon. ${ }^{2}$ Department of General and Scientific Studies, IUT-FV Bandjoun, University of Dschang, P.O. Box 134, Bandjoun, Cameroon. ${ }^{3}$ Department of Physics, Faculty of Science, University of Maroua, P.O. Box 814, Maroua, Cameroon. ${ }^{4}$ Department of Renewable Energy, Polytechnic of Sahel, University of Maroua, P.O. Box 46, Maroua, Cameroon. ${ }^{5}$ Department of Physics, Faculty of Science, University of Yaoundé I, P.O. Box 812, Yaounde, Cameroun. 
building blocks, the dependence of the microscopic optical properties on the molecular structure, and the differences between the isolated properties of the doped molecule when inserted in a macroscopic devices is of fundamental importance. Therefore, systematic quantum chemical calculations on doped molecule can significantly contribute to our understanding of the electronic and optical properties with promising optoelectronic applications since most of these properties pertain to the molecular structure.

As part of a more extensive research on organic molecules [14-26], and following our previous works on coronene (a polycyclic aromatic hydrocarbon of the circumacene class) [17], we present in this paper a comprehensive comparative theoretical study of Coronene and Coronene substituted with Chlorine usng TD-DFT ((TDWB97XD, TD-B3LYP) and TD-LSDA and TD-CCSD(T)). The choice of this molecule was motivated by the availability of reliable experimental data for undoped coronene and theoretical results for doped coronene molecule. Equally, circumacenes are promising candidates for organic and molecular electronics [27]. Furthermore, as reported in literature, the modification of polycyclic aromatic hydrocarbons and conjugate pi-electron systems with strong electronegative substituent is an effective approach for converting $p$-type organic semiconductors to $n$-type [28-30]. The study was motivated by the fact that the electrical properties of semiconductor materials are significantly altered by presence of impurity atoms which are responsible for the development of transistors and has opened up the entire field of solid state device technology. Equally, $n$-type materials from polycyclic aromatic hydrocarbons can be obtain by attaching strong electronwithdrawing groups such as $\mathrm{CN}$ to the conjugated core, or by replacing some or all of the peripheral hydrogen atoms with halogen atoms (in particular $\mathrm{F}$ and $\mathrm{Cl}$ ) [12, 29-31]. Functionalized coronene [32-35] and other organic compounds [35-37] are of profound interest nowadays for the fabrication of organic field effect transistors OFETs and organic thin film transistors (OTFTs) for better performance $[37,38]$. Sanyal et al. 2013 investigated the effect of imide functionalization on the electronic, optical, and charge transport properties of coronene derivatives(coronene5-diimide, coronene-6-diimide, and coronene-tetraimide) and their results suggested that these imide functionalized coronene have potential use in optoelectronic and field effect transistor devices [39].

They equally studied the energetics, photophysical properties, charge transfer integrals and reorganization energy of coronene and its various imide derivatives using DFT methods and their results showed that the introduction of imide functional group, an electron acceptor, strongly modulates the charge transfer behaviors of coronene [39]. Moreover, calculations on the electronic properties of solid coronene doped with potassium has demonstrated superconductivity as reported in literature [40-42].

There are many situations in which a judicious control of the types and amounts of imperfections can bring about specific characteristics desired in a system which can be achieved by proper processing techniques. The effects of imperfections or crystal defects and functionalization have some important properties of solids. The fact that such small amounts of impurity atoms can significantly alter the electrical properties of semiconductors and other organic materials is responsible for the development of transistor, light-emitting diodes [4] and photovoltaic cells [5] and has opened up the entire field of solid state device technology. Practically most of the semiconducting properties that led to this engineering are not found in a perfect crystal.

Our main objective is to see how some of the properties of coronene like electronic, optoelectronic, linear and nonlinear optical properties and UV-Vis Spectrum can be improved by doping the molecule with chlorine. This is because since chlorine atom has a high electron affinity, large dipole moment and effective delocalization of the $\mathrm{pi}$ - electrons, the introduction of the chlorine atom to the coronene may be a good choice to construct a high acceptor molecule. Also, since fluorine atom has been widely introduce into organic semiconductors material to synergistically improve the molecular energy level, optical absorption and carrier mobility properties for photovoltaic applications, due to it high electronegativity and small atomic radius [30,43-46], we think that chlorine atom can do same. Equally, Kan et al. 2018 [47] showed that the chlorination of small-molecule acceptor for organic solar cells reduces the optical band gap, the energy loss, increases the efficiency of the molecule and broaden the effective absorption range.

\section{Computational methodology}

The electronic structure, the structural parameters and the vibrational analysis of Coronene and Coronene substituted with Chlorine were optimized with the aid of the Gaussian 09 program package [48]. Following our previous studies on coronene, the geometry optimization was carried out using the RHF, WB97XD and B3LYP hybrid exchange-correlation functional in combination with the correlationconsistent polarized Valence Double Zeta basis-set [17]. In this work, geometric optimizations of the electronic structure of the molecules were fully optimized using TD-DFT (TD-wB97XD, TD-B3LYP, TD-SVWN (LSDA) and TD$\operatorname{CCSD}(T)$ ) with correlation-consistent polarized Valence Double Zeta basis set. The TD-DFT was performed using 
the route section in the Gaussian 09 by define the Nstates (the number of excited states) with the method used. In all cases, structural optimizations were performed without any symmetry constraints and the optimized geometric structures were confirmed as correct minima by the vibrational frequency analyses. These optimized stationary points characterized by harmonic vibrational frequency analyses confirm that local minima were found due to the absence of imaginary vibrational frequencies. The minimum energy configurations of chlorinated coronene obtained by complete peripheral Chlorine substitution and by substituting 6 hydrogen atoms with 6 chlorine atoms maintained the planar geometry of the substituted Coronene molecule. The adiabatic electron affinities and ionization energies were calculated using the total energy differences. The vertical ionization energies $\left(\mathrm{IE}_{\mathrm{V}}\right)$ and electron affinities $\left(E A_{V}\right)$ were evaluated at the relaxed geometry of the neutral molecule. This enabled us to calculate the quasi-particle corrected energy gap which is defined in the self consistent field scheme as: $E_{\mathrm{Qpg}}=\mathrm{IE}_{\mathrm{V}}-\mathrm{EA}_{\mathrm{V}}=\left(\mathrm{E}_{\mathrm{N}+1}-\right.$ $\left.E_{N}\right)-\left(E_{N}-E_{N-1}\right)[49,50]$, where $E_{N}$ is the total energy of the $\mathrm{N}$-electron system.

The $\mathrm{E}_{\mathrm{HOMO}}, \mathrm{E}_{\mathrm{LUMO}}$ and related properties such as electronegativity $\varsigma$, chemical hardness $\xi$ and chemical softness $\vartheta$ were also determined. The quantities $\varsigma, \xi$ and $\vartheta$ were better discussed in terms of expressions given in literature [14, 51, 52]. The IP and EA of the molecules were calculated using the equations $I P=-E_{\mathrm{HOMO}}$ and $E A=-E_{\mathrm{LUMO}}$ found in literature $[15,16,53]$.

Thus, the values of $\varsigma$ and $\xi$ according to Pearson, were evaluated using the following relations [54]: $\varsigma=\frac{I P+E A}{2}$ and $\xi=\frac{I P-E A}{2}$. The chemical softness $\vartheta$, which describes the ability of an atom or group of atoms to receive electrons [55] was estimated by using the equation: $\vartheta=\frac{1}{\xi}=\frac{2}{I P-E A}$. The chemical softness is proportional to the magnitude of the electrical conductivity. The electrical conductivity of organic materials usually exhibits a thermally activated behavior. Experimental data obtained on high-quality single crystals indicate that the appearance of an activated transport is in many instances more likely due to the presence of structural disorder and chemical defects rather than corresponding to the intrinsic signature of polaron formation. The chemical hardness of the molecules gives us information on how the electron cloud can be deformed. From the maximum hardness principle, which states that the most stable systems are correlated with higher chemical hardness and therefore correspond to larger HOMO-LUMO energy gaps. Low hardness, which correlates to small HOMO-LUMO energy gaps correspond to easily deformable electron cloud.

\section{Results and discussion}

\subsection{Optimized geometric structure of coronene $\left(\mathrm{C}_{24} \mathrm{H}_{12}\right)$ and coronene substituted with chlorine}

The optimized structure of coronene $\left(\mathrm{C}_{24} \mathrm{H}_{12}\right)$, that obtained when 6 hydrogen atoms are substituted by 6 chlorine atoms $\left(\mathrm{C}_{24} \mathrm{H}_{6} \mathrm{Cl}_{6}\right)$ and the complete peripheral chlorine substitution $\left(\mathrm{C}_{24} \mathrm{Cl}_{12}\right)$ are shown in Fig. $1 \mathrm{a}-\mathrm{C}$ respectively. We observed that the planar geometry of the molecule did not change compared to the original planar molecular structure for complete peripheral and partial chlorine substituted coronene.

\subsection{Dipole moment, first molar hyperpolarizability and second molecular hyperpolarizability}

The values of the dipole moment, first molar hyperpolarizability and second molecular hyperpolarizability of $\mathrm{C}_{24} \mathrm{H}_{12}$, $\mathrm{C}_{24} \mathrm{H}_{6} \mathrm{Cl}_{6}$ and $\mathrm{C}_{24} \mathrm{Cl}_{12}$ are reported in Table 1.
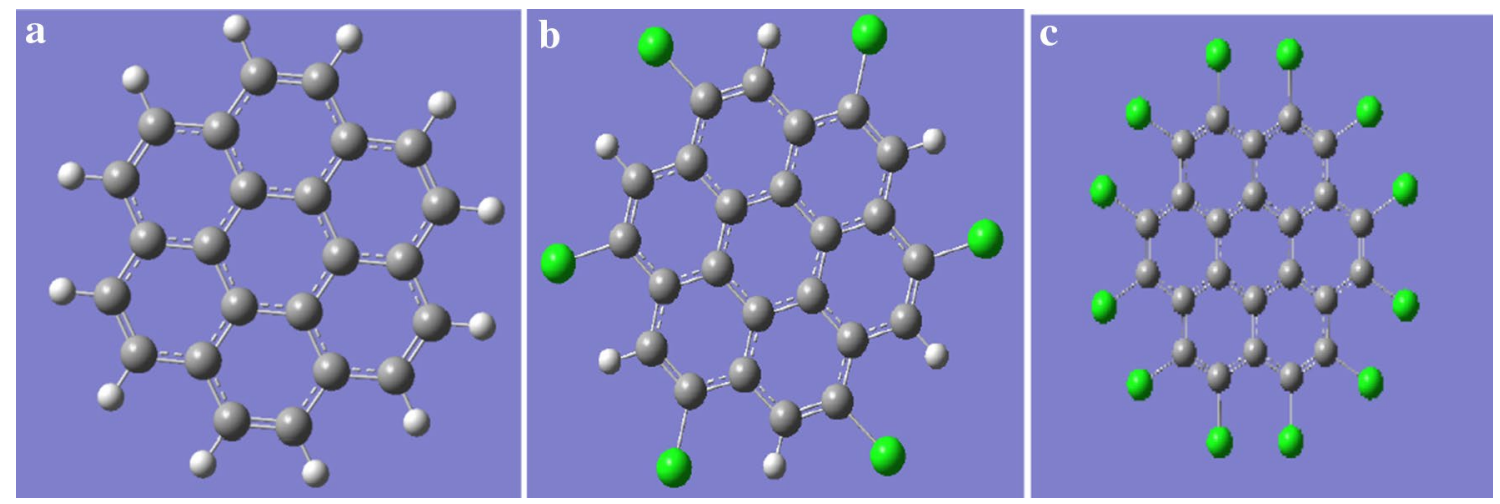

Fig. 1 a Optimized structure of Coronene $\left(\mathrm{C}_{24} \mathrm{H}_{12}\right)$, grey balls are $\mathrm{C}$ atoms, white are $\mathrm{H}$ atoms. b Optimized structure of $\mathrm{C}_{24} \mathrm{H}_{6} \mathrm{Cl}_{6}, \mathrm{grey}$ balls are $\mathrm{C}$ atoms, white are $\mathrm{H}$ atoms and green are $\mathrm{Cl}$. $\mathrm{c}$ Optimized structure of $\mathrm{C}_{24} \mathrm{Cl}_{12}$, grey balls are $\mathrm{C}$ atoms and green are $\mathrm{Cl}$ atoms 
Table 1 Dipole moment $\mu$, first molecular hyperpolarizability $\beta_{\text {mol }}$ second molecular hyperpolarizability $\gamma_{a v}$, total electronic energy $E_{0}$, LUMO-HOMO Energy band gap $E_{\mathrm{g}}$, Ionization potential IP, Electron affinity $\mathrm{EA}$, Kohn-Sham HOMO-LUMO gap $E_{\mathrm{gS}}^{\mathrm{KS}}$, quasi-particle energy corrected gap $E_{\mathrm{Qpg}}$, work function $E_{\mathrm{F}}$, chemical hardness $\xi$, chemical softness $\vartheta$, and electronegativity $\varsigma$ of the molecules Coronene and coronene doped with Chlorine atom obtained at the TD-wB97XD, TD-B3LYP, TD-SVWN (LSDA) and TD-CCSD(T) level of theory using the cc-pVDZ basis set

\begin{tabular}{|c|c|c|c|c|c|}
\hline Molecule & $\begin{array}{l}\text { Basis set/properties of } \\
\text { the molecule }\end{array}$ & TD-wB97XD/cc-pVDZ & TD-B3LYP/cc-pVDZ & TD-SVWN/cc-pVDZ & $\mathrm{TD}-\mathrm{CCSD}(\mathrm{T}) / \mathrm{cc}-\mathrm{pVDZ}$ \\
\hline \multirow[t]{15}{*}{$\mathrm{C}_{24} \mathrm{H}_{12}$} & $\mu(\mathrm{Cm}) \times 10^{-33}$ & 2.67 & 2.33 & 2.67 & 3.00 \\
\hline & $\beta_{\mathrm{mol}}(\mathrm{esu}) \times 10^{-36}$ & 7.33 & 6.97 & 4.65 & 1.23 \\
\hline & $\gamma_{a v}(\mathrm{esu}) \times 10^{-33}$ & $-23,382.68$ & $-23,789.15$ & $-23,562.22$ & $23,687.41$ \\
\hline & $\mathrm{E}_{0}(\mathrm{a} . \mathrm{u})$ & -921.64 & -921.95 & -916.62 & -916.01 \\
\hline & $\mathrm{IP}(\mathrm{eV})$ & $8.99(7.36)$ & $8.99(5.66)$ & $8.99(5.83)$ & $8.99(7.08)$ \\
\hline & $\mathrm{EA}(\mathrm{eV})$ & $6.04(0.05)$ & $6.04(1.59)$ & $6.04(2.89)$ & $6.04(1.65)$ \\
\hline & $\mathrm{IP}_{\mathrm{v}}(\mathrm{eV})$ & 7.41 & 7.15 & 7.22 & 7.28 \\
\hline & $\mathrm{EA}_{\mathrm{v}}(\mathrm{eV})$ & 0.60 & 0.45 & 0.58 & 0.53 \\
\hline & $E_{\mathrm{g}}(\mathrm{eV})$ & 2.95 & 2.95 & 2.95 & 2.95 \\
\hline & $E_{\mathrm{Qpg}}(\mathrm{eV})$ & 6.81 & 6.70 & 6.64 & 6.75 \\
\hline & $E_{\mathrm{g}}^{\mathrm{KS}}(\mathrm{eV})$ & 7.31 & 4.07 & 2.94 & 5.44 \\
\hline & $E_{F}(e V)$ & -7.52 & -7.52 & -7.52 & -7.52 \\
\hline & $\varsigma$ & 7.52 & 7.52 & 7.52 & 7.52 \\
\hline & $\vartheta$ & 0.68 & 0.68 & 0.68 & 0.68 \\
\hline & $\xi$ & 1.48 & 1.48 & 1.48 & 1.48 \\
\hline \multirow[t]{15}{*}{$\mathrm{C}_{24} \mathrm{H}_{6} \mathrm{Cl}_{6}$} & $\mu(\mathrm{Cm}) \times 10^{-34}$ & 3.33 & 3.33 & 0.87 & 6.67 \\
\hline & $\beta_{\mathrm{mol}}(\mathrm{esu}) \times 10^{-35}$ & 8.87 & 8.81 & 8.84 & 10.21 \\
\hline & $\gamma_{a v}(\mathrm{esu}) \times 10^{-33}$ & $-62,491.90$ & $--62,612.47$ & $-61,803.06$ & $-63,969.46$ \\
\hline & $\mathrm{E}_{0}(\mathrm{a} . \mathrm{u})$ & -3679.24 & -3679.64 & -3667.46 & -3669.50 \\
\hline & $\mathrm{IP}(\mathrm{eV})$ & $8.52(8.14)$ & $8.52(6.37)$ & $8.52(6.45)$ & $8.52(8.01)$ \\
\hline & $\mathrm{EA}(\mathrm{eV})$ & $5.97(1.04)$ & $5.59(2.50)$ & $5.59(3.73)$ & $5.59(2.97)$ \\
\hline & $\mathrm{IP}_{\mathrm{A}}(\mathrm{eV})$ & 8.46 & 8.31 & 8.38 & 8.40 \\
\hline & $\mathrm{EA}_{\mathrm{A}}(\mathrm{eV})$ & 1.74 & 1.87 & 2.00 & 1.92 \\
\hline & $E_{\mathrm{g}}(\mathrm{eV})$ & 2.59 & 2.59 & 2.59 & 2.59 \\
\hline & $E_{\mathrm{Qpg}}(\mathrm{eV})$ & 6.72 & 6.44 & 6.38 & 6.48 \\
\hline & $E_{\mathrm{g}}^{\mathrm{KS}}(\mathrm{eV})$ & 7.10 & 3.87 & 2.72 & 5.04 \\
\hline & $E_{\mathrm{F}}(\mathrm{eV})$ & -7.23 & -7.23 & -7.23 & -7.23 \\
\hline & $\varsigma$ & 7.25 & 7.25 & 7.25 & 7.25 \\
\hline & $\vartheta$ & 0.78 & 0.78 & 0.78 & 0.78 \\
\hline & $\xi$ & 1.28 & 1.28 & 1.28 & 1.28 \\
\hline \multirow[t]{12}{*}{$\mathrm{C}_{24} \mathrm{Cl}_{12}$} & $\mu(\mathrm{Cm}) \times 10^{-34}$ & 0.001 & 0.001 & 3.33 & 13.33 \\
\hline & $\beta_{\mathrm{mol}}(\mathrm{esu}) \times 10^{-35}$ & 0.02 & 0.02 & 0.16 & 0.19 \\
\hline & $\gamma_{a v}(\mathrm{esu}) \times 10^{-33}$ & $-98,944.19$ & $-494,496.67$ & $-402,436.11$ & $-506,391.43$ \\
\hline & $E_{0}(\mathrm{a} . \mathrm{u})$ & -6436.47 & -6436.95 & -6417.98 & -6422.56 \\
\hline & $\mathrm{IP}(\mathrm{eV})$ & $7.15(8.28)$ & $7.15(6.27)$ & $7.15(5.87)$ & $7.15(8.42)$ \\
\hline & $\mathrm{EA}(\mathrm{eV})$ & $5.69(1.58)$ & $5.69(2.95)$ & $5.69(4.10)$ & $5.69(0.18)$ \\
\hline & $E_{\mathrm{g}}(\mathrm{eV})$ & 1.46 & 1.46 & 1.46 & 1.46 \\
\hline & $E_{\mathrm{g}}^{\mathrm{KS}}(\mathrm{eV})$ & 6.70 & 3.32 & 1.77 & 8.24 \\
\hline & $E_{F}(e V)$ & -6.42 & -6.42 & -6.42 & -6.42 \\
\hline & $\varsigma$ & 6.42 & 6.42 & 6.42 & 6.42 \\
\hline & $\vartheta$ & 1.37 & 1.37 & 1.37 & 1.37 \\
\hline & $\xi$ & 0.73 & 0.73 & 0.73 & 0.73 \\
\hline
\end{tabular}

Chemical hardness $\xi$, chemical softness $\vartheta$, and electronegativity $\varsigma$ are unitless quantities 
The first molecular hyperpolarizability $\beta_{m o l}$ can be calculated from the Gaussian output file by using equation found in literature $[12,14,15,52,55-58]$. The $\beta_{\text {mol }}$ value of the molecules was determined using the equation below given in literature $[14,15,19-21,59]$.

$$
\begin{aligned}
\beta_{\mathrm{mol}}= & {\left[\left(\beta_{x x x}+\beta_{x y y}+\beta_{x z z}\right)^{2}+\left(\beta_{y y y}+\beta_{y x x}+\beta_{y z z}\right)^{2}\right.} \\
& \left.+\left(\beta_{z z z}^{2}+\beta_{z x x}+\beta_{z y y}\right)^{2}\right]^{\frac{1}{2}}
\end{aligned}
$$

The values of $\beta_{\mathrm{mol}}$ for the molecules are small compared to that of Urea given in literature $[20,21,57,58$, $60]$. Due these relatively small values of $\beta_{\mathrm{mol}}$, we decided to calculate the second order hyperpolarizability.

The second order hyperpolarizability $\gamma_{a v}$ which is a microscopic property of the molecules was also determined and calculated $\gamma_{a v}$ values in atomic unit were converted into SI units using conversion factors given in literature $[17,56]$. The values of $\gamma_{a v}$ were determined by using the equation $[17,61,62]$ $\gamma_{a v}=\frac{\gamma_{x x x x}+\gamma_{y y y y}+\gamma_{z z z z}+2 \gamma_{x x y y}+2 \gamma_{y y z z}+2 \gamma_{x x z z}}{5}$

The results showed that $\gamma_{x x x x}$ and $\gamma_{y y y y}$ which are the tensor components of $\gamma$ in the $x$ and $y$ directions respectively gave the highest contribution in the calculation of $\gamma_{a v}$ and these tensor components are approximately the same. From Table 1, it is observed that all $\gamma_{a v}$ values are negative which indicates that the contributions to $\gamma_{a v}$ is due to the pi electrons except for the molecule $\mathrm{C}_{24} \mathrm{H}_{12}$ that we obtained a positive value at the TDCCSD(T) level. This implies that in calculating the $\gamma_{a v}$ of the molecule $\mathrm{C}_{24} \mathrm{H}_{12}$ at the TD-CCSD(T) level, the contribution was due to the pi and sigma bonds with the sigma bond giving the highest contribution. The TDB3LYP method gave the highest values of $\gamma_{a v}$ for the molecule $\mathrm{C}_{24} \mathrm{H}_{12}$ compared to that obtained using the WB97XD, TD-SVWN and TD-CCSD(T) while that of the TD-CCSD(T) was the largest for the $\mathrm{C}_{24} \mathrm{H}_{6} \mathrm{Cl}_{6}$ molecule. We also observed that with the complete peripheral chlorine substitution of the hydrogen atoms in Coronene $\left(\mathrm{C}_{24} \mathrm{Cl}_{12}\right)$, the $\gamma_{a v}$ values are greater than those obtained from $\mathrm{C}_{24} \mathrm{H}_{6} \mathrm{Cl}_{6}$ and $\mathrm{C}_{24} \mathrm{H}_{12}$ with that of $\mathrm{C}_{24} \mathrm{H}_{6} \mathrm{Cl}_{6}$ greater than that of $\mathrm{C}_{24} \mathrm{H}_{12}$ at all the levels of study. For instance, the $\gamma_{a v}$ value of $\mathrm{C}_{24} \mathrm{Cl}_{12}$ obtained by using the TD-SVWN (LSDA) is approximately 6.5 times larger than that of $\mathrm{C}_{24} \mathrm{H}_{6} \mathrm{Cl}_{6}$ and that of $\mathrm{C}_{24} \mathrm{H}_{6} \mathrm{Cl}_{6}$ is approximately 2.6 times greater than that of $\mathrm{C}_{24} \mathrm{H}_{12}$. It implies that as the number of peripheral Chlorine atoms substitution increases, the $\gamma_{a v}$ value also increases. The large values of $\gamma_{a v}$ permit us to conclude that these molecules have very good linear and nonlinear optical effects and hence can be used in linear and nonlinear materials which may have electronic, optoelectronic and photonic applications. Hence, these molecules may have all or some of the following effects: second harmonic generation, optical rectification, electro-optic Pockel effect, electric induced second harmonic generation and the electro-Kerr effect.

\subsection{Ionization potential IP, electron affinity EA, chemical hardness $\xi$, chemical softness $\theta$, and electronegativity $S$, HOMO-LUMO energy band gap $E_{g}$, work function $E_{F}$, Kohn-Sham HOMO-LUMO energy band gap $E_{g}^{K S}$, quasiparticle energy corrected gap $E_{\mathrm{Qpg}}$, total
Electronic Energy $E_{0}$ and molecular orbital
diagrams of the molecules $\mathrm{C}_{24} \mathrm{H}_{12}$ and $\mathrm{C}_{24} \mathrm{H}_{6} \mathrm{Cl}_{6}$}

The ionization potential, electron affinity, chemical hardness, chemical softness, electronegativity and total Electronic Energy of coronene, when 6 hydrogen atoms are substitute with 6 chlorine atoms and the complete peripheral chlorine substitution obtained by using TD-WB97XD, TD-B3LYP, TD-SVWN (LSDA) and TD-CCSD(T) are shown in Table 1. The IP and AE values were obtained using formulae given in literature $[24,49,53,63]$. The ionization energy values and electron affinity values obtained directly from the Kohn-Sham eigenvalues are given in brackets. The ccpVDZ basis set which is approximately equal to the commonly used 6-31G basis set was employed in all the calculations. Thereafter, we compared our theoretical results with experimental results given in literature. The $\mathbb{I}_{\mathrm{v}}$ results for coronene are closed to the experimental results of the vertical ionization potential $(7.29 \mathrm{eV})$ found in literature [64], the value of $7.34 \mathrm{eV}$ reported by Boschi and Schmidt [65] and to the experimental results of the adiabatic ionization potential given in literature (7.64 eV) [66], $7.29 \mathrm{eV}$ [67] and $(7.29+-0.03) \mathrm{eV}[31,68]$. Our estimated $\mathrm{EA}_{v}$ value of coronene are close to the experimental adiabatic electron affinity values $(0.47+-0.09) \mathrm{eV})[31]$ and the theoretical values ( $0.47 \mathrm{eV}$ and $0.54 \mathrm{eV}$ ) [69] reported in literature and are the same with those previous reported by using $\mathrm{RFH}$, WB97XD and B3LYP methods with the cc-pVDZ [17].

We equally observed that $\xi, \vartheta$ and $\varsigma$ values of coronene remain unchanged at all the levels of theory. It implies the electrical conductivity of the molecule also remain unchanged since the chemical softness $\xi$ is proportional to the magnitude of the electrical conductivity.

LUMO-HOMO Energy band gap $E_{g^{\prime}}$ work function $E_{\mathrm{F}}$ Kohn-Sham HOMO-LUMO energy band gap $E_{\mathrm{g}}^{\mathrm{KS}}$ and work function $E_{\mathrm{F}}$ of the molecules $\mathrm{C}_{24} \mathrm{H}_{12}, \mathrm{C}_{24} \mathrm{H}_{6} \mathrm{Cl}_{6}$ and $\mathrm{C}_{24} \mathrm{Cl}_{12}$ are given in Table 1 and the molecular orbital diagrams are shown in Fig. 2. The $E_{\mathrm{g}}$ value determined for coronene is the same as that obtained in our previous studies by using RHF, wB97XD and B3LYP methods with the cc-pVDZ [17] and smaller than the theoretical value reported in 

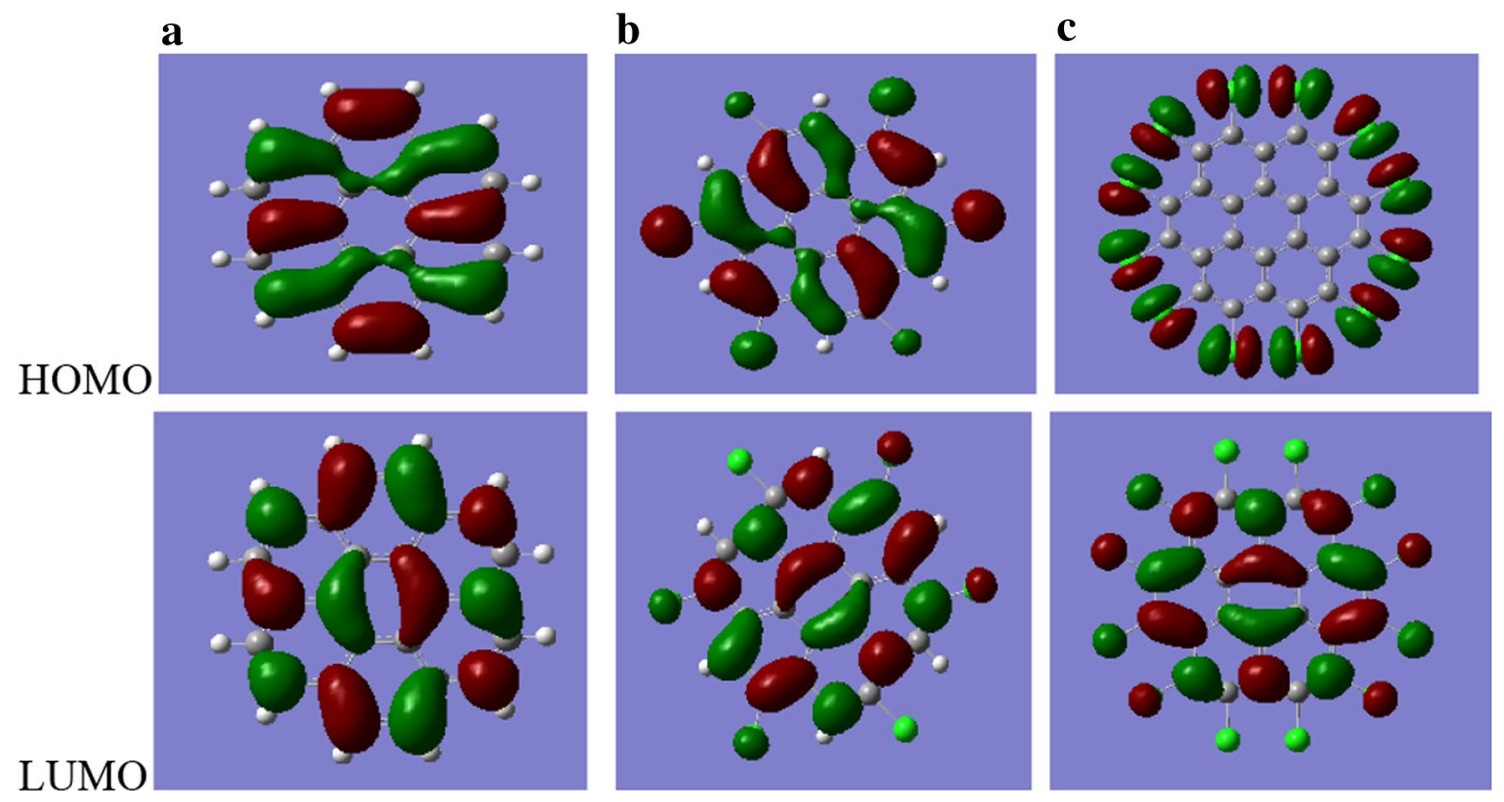

Fig. 2 a HOMO and LUMO molecular orbital diagrams for Coronene $\left(\mathrm{C}_{24} \mathrm{H}_{12}\right)$. b HOMO and LUMO molecular orbital diagrams for $\mathrm{C}_{24} \mathrm{H}_{6} \mathrm{Cl}_{6}$. c $\mathrm{HOMO}$ and LUMO molecular orbital diagrams for $\mathrm{C}_{24} \mathrm{Cl}_{12}$

Table 2 Singlet-singlet permitted excitation energies $E_{\text {excit }}$ (in eV) and corresponding oscillator strength $f$ of unsubstituted and chlorinated coronene as obtained by TD-DFT at the TD-wB97XD, TD-
B3LYP, TD-SVWN (LSDA) and TD-CCSD(T) level of theory using the cc-pVDZ basis set. Values of $E_{\text {excit }}$ and $\mathrm{f}$ given in brackets correspond to the excited state in bracket

\begin{tabular}{|c|c|c|c|c|c|c|c|c|}
\hline \multicolumn{9}{|l|}{$\mathrm{C}_{24} \mathrm{H}_{12}$} \\
\hline \multirow{2}{*}{$\begin{array}{l}\text { Method/basis set } \\
\text { Excited state }\end{array}$} & \multicolumn{2}{|c|}{ TD-wB97XD/cc-pVDZ } & \multicolumn{2}{|c|}{ TD-B3LYP/cc-pVDZ } & \multicolumn{2}{|c|}{ TD-SVWN/cc-pVDZ } & \multicolumn{2}{|c|}{ TD-CCS(T)/cc-pVDZ } \\
\hline & $E_{\text {excit }}(\mathrm{eV})$ & $F$ & $E_{\text {excit }}(\mathrm{eV})$ & $F$ & $E_{\text {excit }}(\mathrm{eV})$ & $F$ & $E_{\text {excit }}(\mathrm{eV})$ & $F$ \\
\hline 1 & 3.57 & 0.00 & 3.29 & 0.00 & 2.98 & 0.00 & 4.22 & 0.00 \\
\hline 2 & 3.87 & 0.00 & 3.48 & 0.00 & 3.18 & 0.00 & 4.27 & 0.00 \\
\hline 3 & 4.73 & 1.02 & 4.16 & 0.64 & 3.75 & 0.44 & 5.44 & 0.64 \\
\hline 4 & 4.73 & 1.02 & 4.16 & 0.64 & 3.75 & 0.44 & 5.51 & 0.64 \\
\hline $5(30)$ & 4.75 & 0.00 & 4.33 & 0.00 & 3.86 & 0.00 & $(8.37)$ & $0.00(2.47)$ \\
\hline $6(31)$ & 4.75 & 0.00 & 4.33 & 0.00 & 3.88 & 0.00 & $(8.37)$ & $0.00(2.47)$ \\
\hline Excited state & $\mathrm{C}_{24} \mathrm{H}_{6} \mathrm{Cl}_{6}$ & & & & & & & \\
\hline 1 & 3.44 & 0.00 & 3.11 & 0.00 & 2.76 & 0.00 & 4.13 & 0.00 \\
\hline $2(8)$ & 3.72 & 0.00 & 3.31 & 0.00 & 2.95 & 0.00 & $4.18(5.68)$ & $0.00(2.71)$ \\
\hline $3(9)$ & 4.49 & 2.17 & 3.90 & 0.72 & 3.42 & 0.47 & $5.38(5.68)$ & $0.00(2.71)$ \\
\hline $4(17)$ & 4.49 & 2.17 & 3.90 & 0.72 & $3.42(4.56)$ & $0.47(0.01)$ & $5.49(7.25)$ & $0.00(0.002)$ \\
\hline $5(18)$ & $4.63(6.10)$ & $0.00(0.013)$ & $4.17(5.34)$ & $0.00(0.005)$ & $3.62(4.56)$ & $0.00(0.01)$ & $5.49(7.25)$ & $0.00(0.002)$ \\
\hline $6(19)$ & $4.63(6.10)$ & $0.00(0.013)$ & $4.17(5.34)$ & $0.00(0.005)$ & 3.63 & 0.00 & 5.60 & 0.00 \\
\hline 20 & - & - & 5.34 & 0.005 & & & & \\
\hline $21(22)$ & - & - & 5.34 & 0.005 & $(4.62)$ & $(0.06)$ & & \\
\hline 23 & - & - & 5.51 & 0.12 & 4.62 & 0.06 & & \\
\hline 24 & - & - & 5.51 & 0.12 & - & - & 7.45 & 0.24 \\
\hline $27(25)$ & 6.38 & 0.18 & 5.70 & 0.16 & - & - & $(7.45)$ & $(0.24)$ \\
\hline 28 & 6.38 & 0.18 & 5.70 & 0.16 & & & & \\
\hline $31(37)$ & - & - & - & - & $(4.93)$ & $(0.08)$ & $8.20(8.69)$ & (0.06) 2.50 \\
\hline $32(38)$ & 6.66 & 1.01 & $(5.85)$ & $(0.15)$ & $(4.93)$ & $(0.08)$ & $8.20(8.69)$ & $2.50(0.06)$ \\
\hline 34 (39) & 6.66 & 1.01 & $(5.85)$ & $(0.15)$ & - & - & $(8.75)$ & $(0.42)$ \\
\hline 40 & - & - & - & - & - & - & 8.75 & 0.42 \\
\hline
\end{tabular}


literature $(4.3 \mathrm{eV})$ [31] obtained using B3LYP/def2-TZVP method. The $E_{\text {gap }}$ and $E_{\mathrm{F}}$ value did not change at all levels of study. From Table 2, it is observed that when coronene is doped with $\mathrm{Cl}$ (when we substitute 6 atoms of hydrogen with 6 atoms of chlorine), the $E_{\mathrm{g}}$ decreases while $E_{\mathrm{F}}$ values increases. Comparing the $E_{\mathrm{g}}$ values of $\mathrm{C}_{24} \mathrm{H}_{6} \mathrm{Cl}_{6}$ and $\mathrm{C}_{24} \mathrm{Cl}_{12}$ with that of coronene when doped with an atom of $\mathrm{Cl}\left(\mathrm{C}_{24} \mathrm{H}_{11} \mathrm{Cl}\right)$, with an atom of $\mathrm{F}\left(\mathrm{C}_{24} \mathrm{H}_{11} \mathrm{~F}\right)$ [31], with the peripheral substitution of all hydrogen atoms by fluorine atoms $\mathrm{C}_{18} \mathrm{~F}_{12}$ [30] and $\mathrm{Co}$ (coronene) [70] given in literature, our studies reveal that there is increase conductivity. From our previous studies, we observed that the $E_{\mathrm{g}}$ values of $\mathrm{C}_{24} \mathrm{H}_{6} \mathrm{Cl}_{6}$ and $\mathrm{C}_{24} \mathrm{Cl}_{12}$ are less than that of Coronene doped with $\mathrm{B}, \mathrm{N}$, and $\mathrm{BN}$ [17]. As reported in literature, the modification of polycyclic aromatic hydrocarbons with strong electronegative substituent is an effective approach for converting $p$-type organic semiconductors to $n$-type [28-30]. Typically, $n$-type materials based on polycyclic aromatic hydrocarbons are obtained by attaching strong electron-withdrawing groups such as $\mathrm{CN}$ to the conjugated core, or by replacing the peripheral hydrogens with halogen atoms (in particular $\mathrm{F}$ and $\mathrm{Cl}$ ) $[29,30]$ hence, $\mathrm{C}_{24} \mathrm{H}_{6} \mathrm{Cl}_{6}$ and $\mathrm{C}_{24} \mathrm{Cl}_{12}$ can be used as $n$-type semiconductors. From our results, the calculated $E_{\mathrm{g}}$ value at all levels of theory show that charge transfer occurs within these molecules. The associated $E_{\mathrm{g}}$ of the doped $\mathrm{C}_{18} \mathrm{H}_{6} \mathrm{C}_{16}$ molecule is $2.59 \mathrm{eV}$ which is within the range of electrochemically and optically $E_{\mathrm{g}}$ values of thin films (2.08-2.77 eV) as documented in literature [71] while the $E_{\mathrm{g}}$ value of $\mathrm{C}_{24} \mathrm{Cl}_{12}$ molecule is $1.46 \mathrm{eV}$ smaller than the $E_{\mathrm{g}}$ values of thin films and that of some inorganic semiconductors. Futhermore, we observed that our $E_{\mathrm{g}}$ values for the doped coronene are lower than that of potassium doped coronene [72] reported in literature. Hence we can conclude that these molecules have very good electronic, optoelectronic and photonic applications.

The work function $E_{\mathrm{F}}$ of the molecules reported was obtained from the Fermi energy $[17,73] E_{F}=E_{\mathrm{HOMO}}+\frac{E_{\text {gap }}}{2}$,

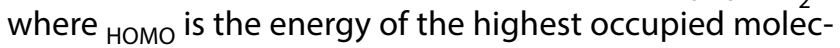
ular orbital and $E_{\text {gap }}$ is the band gap of the system. The $E_{\mathrm{F}}$ value for $\mathrm{C}_{24} \mathrm{H}_{12}$ is $-7.52 \mathrm{eV},-7.23 \mathrm{eV}$ for $\mathrm{C}_{24} \mathrm{H}_{6} \mathrm{Cl}_{6}$ and $-6.42 \mathrm{eV}$ for $\mathrm{C}_{24} \mathrm{Cl}_{12}$ molecule for all the methods. In general, our study reveal that the complete substitution of the peripheral hydrogen atoms with chlorine in the coronene $\left(\mathrm{C}_{24} \mathrm{Cl}_{12}\right)$ molecule gives rise to a decrease in ionization energy, electron affinity, total electronic energy, electronegativity, LUMO-HOMO energy gap, chemical hardness and an increase in the chemical softness, second order hyperpolarizability, excitation wavelength, absorption coefficient and the Fermi energy. Due to the large chemical softness of the molecules, it implies the molecules have a high electrical conductivity since the chemical softness is proportional to the magnitude of the electrical conductivity with $\mathrm{C}_{24} \mathrm{Cl}_{12}$ being a better conductor compared to $\mathrm{C}_{24} \mathrm{H}_{12}$ and $\mathrm{C}_{24} \mathrm{H}_{6} \mathrm{Cl}_{6}$. The order of increase conductivity is as follows: the conductivity of $\mathrm{C}_{24} \mathrm{Cl}_{12}$ greater than that of $\mathrm{C}_{24} \mathrm{H}_{6} \mathrm{Cl}_{6}$ and that of $\mathrm{C}_{24} \mathrm{H}_{6} \mathrm{Cl}_{6}$ is greater than that of $\mathrm{C}_{24} \mathrm{H}_{12}$. From the above results, we observed an improvement in the electronic, optoelectronic, linear and nonlinear optical properties of chlorine substituted coronene with those of $\mathrm{C}_{24} \mathrm{Cl}_{12}$ being more pronounced compare to those of $\mathrm{C}_{24} \mathrm{H}_{6} \mathrm{Cl}_{6}$.

The HOMO and LUMO molecular orbital diagrams of the molecules are shown in Fig. 2. The HOMO and LUMO molecular orbital diagrams of the molecules $\mathrm{C} 24 \mathrm{H} 18$, C18H6Cl6 and $\mathrm{C}_{24} \mathrm{Cl}_{12}$ obtained using TD-wB97XD, TDB3LYP, TD-SVWN (LSDA) and TD-CCSD(T) methods with the cc-pVDZ basis set are the same.

\subsection{Excitation energy, oscillator strength and UV spectrum}

The computed first singlet-singlet permitted excitation energies of unsubstituted and chlorinated coronene as obtained by TD-DFT at the TD-wB97XD/cc-pVDZ, TD-B3LYP/cc-pVDZ, TD-SVWN (LSDA)/cc-pVDZ and TDCCSD(T)/cc-pVDZ level of theory are reported in Table 2 . Only the values of the first 6 excitation energies of the excited states with corresponding oscillator strength $f$ and all the excited energies with oscillator strength different from zero were reported. TD-CCSD(T)/c-pVDZ method gave the largest excited energies values with the corresponding oscillator strength compared to the other methods for the molecules $\mathrm{C}_{24} \mathrm{H}_{12}$ and $\mathrm{C}_{24} \mathrm{H}_{6} \mathrm{Cl}_{6}$.

The spectra are reported in Figs. 3, 4 and 5. The singlet-singlet excitation energies and the electronic spectra in the visible/near-UV region (UV-vis spectra) were obtained by performing TD-DFT calculations at the TDwB97XD/cc-pVDZ, TD-B3LYP/cc-pVDZ, TD-SVWN (LSDA)/ cc-pVDZ and TD-CCSD(T)/cc-pVDZ levels as employed for the electronic ground-state. The frequency-space implementation of TD-DFT based on the linear response of the density-matrix was used. Here the pole strengths correspond to the oscillator strengths and the poles of the linear response function correspond to vertical excitation energies [30]. The required number of transitions and electronic excitations are limited to the low-energy part of the spectrum. Our restriction is based on the first $42 \mathrm{sin}$ glet-singlet roots which are sufficient to cover the optical window for each molecule in all the cases. The calculated UV-Vis (vertical excitation) spectra of $\mathrm{C}_{24} \mathrm{H}_{12}$ obtained with the TD-wB97XD/cc-pVDZ, TD-B3LYP/cc-pVDZ, TD-SVWN (LSDA)/cc-pVDZ and TD-CCSD(T)/cc-pVDZ methods are shown in Fig. 3. Figure 4 gives the TD-wB97XD/ cc-pVDZ, TD-B3LYP/ cc-pVDZ, TD-SVWN (LSDA)/ cc-pVDZ and TDCCSD(T)/cc-pVDZ UV-Vis Spectra of $C 24 \mathrm{H} 6 \mathrm{Cl} 6$ while the 
Fig. 3 TD-wB97XD, TD-B3LYP, TD-LSDA, TD-CCSD(T) UV-Vis Spectrum of $\mathrm{C}_{24} \mathrm{H}_{12}$ obtained basis set by employing the cc-pVDZ

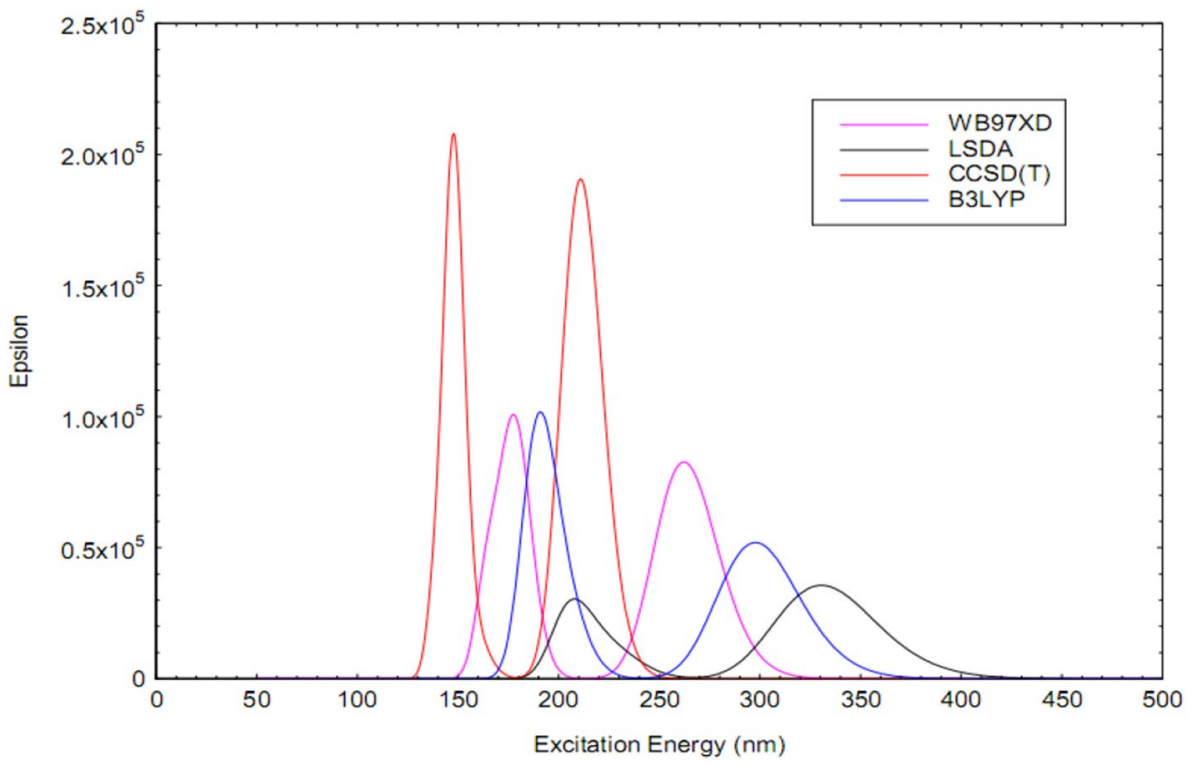

Fig. 4 TD-wB97XD, TD-B3LYP, TD- LSDA, TD- CCSD(T) UV-Vis Spectrum of $\mathrm{C}_{24} \mathrm{H}_{6} \mathrm{Cl}_{6}$ obtained by employing the cc-pVDZ basis set

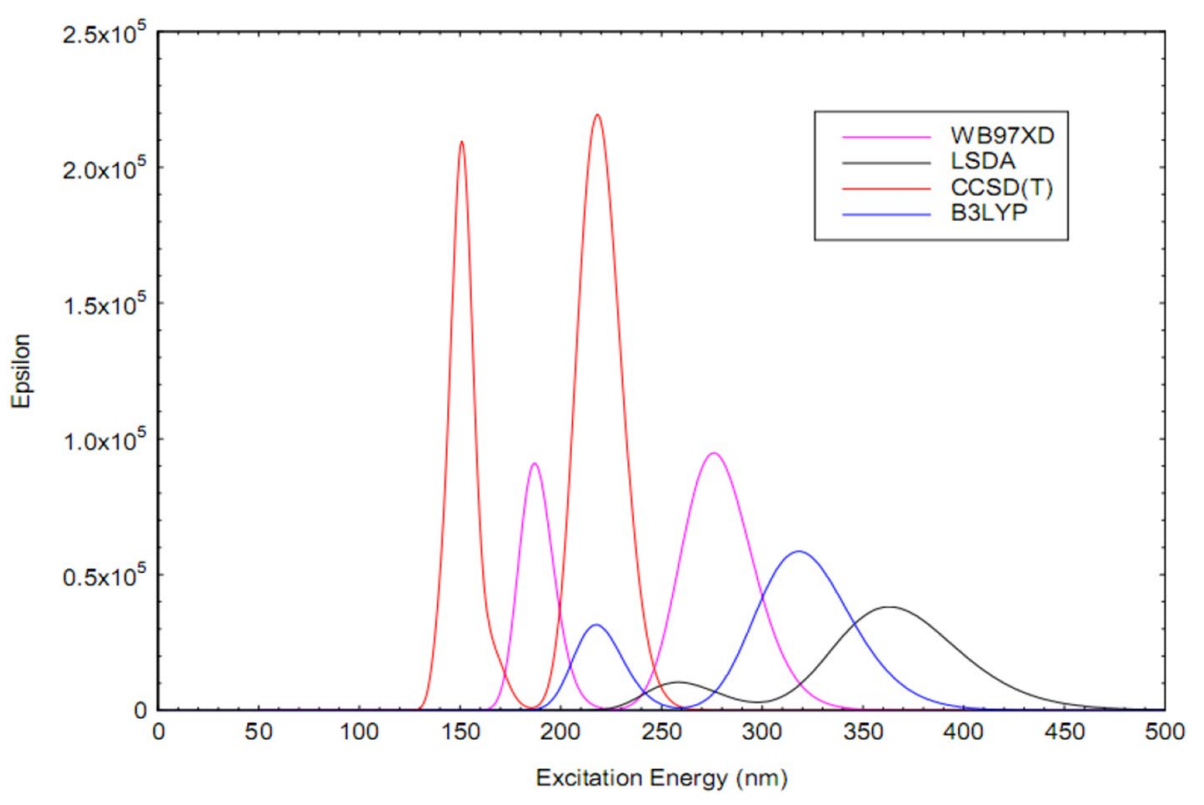

TD-wB97XD/ cc-pVDZ, TD-B3LYP/ cc-pVDZ, TD-SVWN (LSDA)/ cc-pVDZ and TD-CCSD(T)/cc-pVDZ UV-Vis Spectra of $\mathrm{C}_{24} \mathrm{Cl}_{12}$ are given in Fig. 5.

The UV spectrum is made up of large bands which correspond to the superposition of the electronic, vibrational and rotational transitions. The electron transitions are highly energetic, the vibrational transitions are weakly energetic and the rotational transitions are more weakly energetic. The spectra presented in Figs. 3, 4 and 5 present one or two maximum which correspond to the absorption coefficient corresponding to a maximum wavelength, which is more or less as a result of the electron delocalization for organic molecules. The spectra of $\mathrm{C}_{24} \mathrm{H}_{12}$ and $\mathrm{C}_{24} \mathrm{H}_{6} \mathrm{Cl}_{6}$ present two maximum wavelengths while the spectra of $\mathrm{C}_{24} \mathrm{Cl}_{12}$ show one maximum wavelength. EpsiIon on the $y$-axis is a constant which is proportional to the absorption coefficient. From our spectra, we observed that the value of epsilon is higher for $\mathrm{C}_{24} \mathrm{Cl}_{12}$ compare to that of $\mathrm{C}_{24} \mathrm{H}_{6} \mathrm{Cl}_{6}$ and $\mathrm{C}_{24} \mathrm{H}_{12}$ at all level of theory. This implies the wavelength and absorption coefficient are higher when coronene is completely substituted by chlorine at the peripheral. 
Fig. 5 TD- $w B 97 X D, T D-B 3 L Y P$, TD- LSDA, TD- CCSD(T) UV-Vis Spectrum of $\mathrm{C}_{24} \mathrm{Cl}_{12}$ obtained by employing the cc-pVDZ basis set

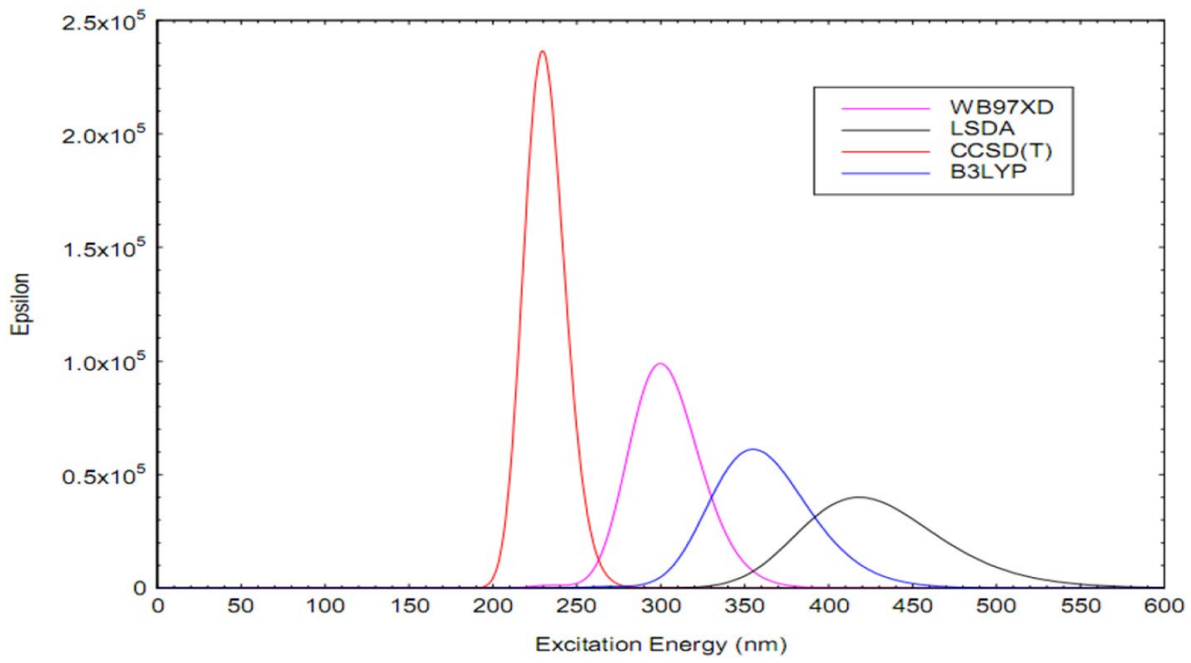

\section{Conclusion}

In this work we have investigated theoretically the electronic, optoelectronic, linear and non linear optical properties and UV-Vis Spectrum of Coronene and Coronene substituted with Chlorine. By means of TD-wB97XD, TDB3LYP, TD-SVWN (LSDA) and TD-CCSD $(T)$ calculations we have quantized the effect of Coronene substituted completely and partially with Chlorine on a series of key molecular properties of interest for solid-state applications. We observed that the partial substitution of 6 peripheral hydrogen atoms with 6 Chlorine atoms in coronene molecule gives rise to increase second order hyperpolarizability, chemical softness, Fermi energy while the ionization energy, electron affinity, chemical hardness, LUMO-HOMO energy gap and dipole moment decrease. The second order hyperpolarizability of the molecule $\mathrm{C}_{24} \mathrm{H}_{6} \mathrm{Cl}_{6}$ obtained using the TD-wB97XD, TDB3LYP, TD-SVWN (LSDA) and TD-CCSD(T)) method is 2.67, $2.63,2.62$ and 2.70 times greater than its corresponding value of coronene respectively. Equally, $E_{\mathrm{g}}^{\mathrm{KS}}$ and $E_{\mathrm{g}}$ values of $\mathrm{C}_{18} \mathrm{H}_{6} \mathrm{C}_{16}$ are smaller than their corresponding values obtained with $\mathrm{C}_{24} \mathrm{H}_{12}$ molecule. Since most of the above quantities change by approximately the same amount, the corresponding quasi-particle corrected energy gap is observed to vary slightly following chemical substitution for all the methods. Hence, the partial or complete substitution of hydrogen atoms in coronene by chlorine atoms or other atoms may give rise to interesting electronic, optoelectronic, linear and nonlinear optical properties of this molecule.

The large values of $\gamma_{a v}$ and $E_{g}$ permit us to conclude that these molecules have very good linear and nonlinear optical effects and hence can be used in linear and nonlinear materials which may have electronic, optoelectronic and photonic applications.

Acknowledgements We are thankful to the Council of Scientific and Industrial Research (CSIR), India for financial support through Emeritus Professor scheme (Grant No21(0582)/03/EMR-II) to late Prof. A.N. Singh of the Physics Department, Bahamas Hindu University, India which enabled him to purchase the Gaussian Software. We are most grateful to Late Emeritus Prof. A.N. Singh for donating this software to Prof. G. W. Ejuh.

\section{Compliance with ethical standards}

Conflict interest The authors declare that there is no conflict of interest as concern this article.

\section{References}

1. Forrest SR (2004) The path to ubiquitous and low-cost organic electronic appliances on plastic. Nature 428:911

2. Anthony JE (2008) The larger acenes: Versatile organic semiconductors. Angew Chem. Int. Ed. Eng. 47(3):452

3. Halik M, Klauk H, Zschieschang U, Kriem T, Schmid G, Radlik W, Wussow K (2002) Fully patterned all-organic thin film transistors. Appl Phys Lett 81:289

4. Kan Y, Wang L, Duan L, Hu Y, Wu G, Qiu Y (2004) Highly-efficient blue electroluminescence based on two emitter isomers. Appl Phys Lett 84:1513

5. Yoo S, Domercq B, Kippelen B (2004) Efficient thin-film organic solar cells based on pentacene/C60 heterojunctions. Appl Phys Lett 85:5427

6. Shiyanovskaya I, Singer KD, Percec V, Bera TK, Miura Y, Glodde M (2003) Charge transport in hexagonal columnar liquid crystals self-organized from supramolecular cylinders based on acenefunctionalized dendrons. Phys. Rev. B 67:035204

7. Anthony JE (2006) Chem Rev 106(12):5028 
8. Murphy AR, Frechet MJ (2007) Functionalized acenes and heteroacenes for organic electronics. Chem Rev 107:1066

9. Huang L, Rocca D, Baroni S, Gubbins KE, Nardelli MB (2009) Molecular design of photoactive acenes for organic photovoltaics. J. Chem. Phys. 130:194701

10. Karak S, Reddy VS, Ray SK, Dhar A (2009) Organic photovoltaic devices based on pentacene/N, N'-dioctyl-3,4,9,10perylenedicarboximide heterojunctions. Org Electron 10:1006

11. De Angelis F (2010) Direct versus indirect injection mechanisms in perylene dye-sensitized solar cells: a DFT/TDDFT investigation. Chem Phys Lett 493:323

12. Bredas J-L, Beljonne D, Coropceanu V, Cornil J (2004) Chargetransfer and energy-transfer processes in pi-conjugated oligomers and polymers: a molecular picture. Chem Rev 104:4971

13. Sancho-Garca JC (2007) Assessment of density-functional models for organic molecular semiconductors: the role of HartreeFock exchange in charge-transfer processes. Chem Phys 331:321

14. Ejuh GE, Tchangnwa Nya F, Djongyang N, Ndjaka JMB (2018) Study of some properties of quinone derivatives from quantum chemical calculations. Optic. Quant. Electron. https://doi. org/10.1007/s11082-018-1603-0

15. Ejuh GW, Tchangnwa Nya F, Yossa Kamsi RA, Ndjaka JMB (2018) Investigation of the Electronic, optoelectronics, Linear and nonlinear optical properties of the molecules Heptacene ([7]acene) $(\mathrm{C} 30 \mathrm{H} 18)$ and [7]acene doped with potassium atom (C3OH9K9). Poly. Bullet. 75(2):537

16. Ejuh GW, Ottou Abe MT, Tchangwa Nya F, Ndjaka JMB (2018) Prediction of electronic structure, dielectric and thermodynamical properties of Flurbiprofen by Density Functional Theory calculation. Karbala J. Mod. Sci. 4:12

17. Ejuh GW, Tchangnwa Nya F, Ottou Abe MT, Fankam Fankam JB, Ndjaka JMB (2017) Electronic structure, physico-chemical, linear and non linear optical properties analysis of coronene, 6B-, $6 \mathrm{~N}-, 3 B 3 \mathrm{~N}$ - substituted $\mathrm{C}_{24} \mathrm{H}_{12}$ using RHF, B3LYP and wB97XD methods. Optic. Quant. Electron. 49(11):382

18. Taura L S, Ndikilar C E, Geh W. Ejuh G W, Muhammad A 2018. RHF and DFT Study of the Molecular and Electronic Properties of $\left(\mathrm{SiO}_{2}\right)_{n}$ and $\left(\mathrm{GeO}_{2}\right)_{n}$ Nanoclusters. Mod. Appl. Sci. 12(9) 1913

19. Tchangnwa Nya F, Ejuh GW, Ndjaka JMB (2017) Theoretical study of optoelectronic and thermodynamic properties of molecule 4- [2- (2-N, N-dihydroxy amino thiophene) vinyl] benzanamine: influence of hydroxyl position. Mater Lett 202:89

20. Ejuh GW, Nouemo S, Tchangnwa Nya F, Ndjaka JMB (2016) Modeling of the electronic, Optoelectronics, photonic and thermodynamics properties of 1, 4-bis (3-carboxyl-3-oxo-prop-1-enyl) benzene molecule. J Iran Chem Soc 13(11):2039

21. Ejuh GW, Nouemo S, Tchangnwa Nya F, Ndjaka JMB (2016) Computational determination of the Electronic and Nonlinear Optical properties of the molecules 2-(4-aminophenyl) Quinoline, 4-(4-aminophenyl) Quinoline, Anthracene Anthraquinone Phenanthrene. Mater Lett 178:221

22. Tadjouteu Assatse Y, Ejuh GW, Yossa Kamsi RA, Tchoffo F, Ndjaka JMB (2019) Theoretical studies of nanostructures modeled by the binding of Uracil derivatives to functionalized $(5,5)$ carbon nanotubes. Chem Phys Lett 731:136602

23. Veved A, Ejuh GW, Djongyang N (2019) Effect of $\mathrm{HfO}_{2}$ on the dielectric, optoelectronic and energy harvesting properties of PVDF. Optic. Quant. Electron. 23(10):330

24. Yossa Kamsi RA, Ejuh GW, Tchoffo F, Mkounga P, Ndjaka JMB (2019) Electronic Structure, Spectroscopic (IR, Raman, UV-Vis, NMR), Optoelectronic, and NLO Properties Investigations of Rubescin E (C31H36O7) Molecule in Gas Phase and Chloroform Solution Using Ab Initio and DFT Method. Adv. Conden. Matt. Phys. ID. https://doi.org/10.1155/2019/4246810

25. Fonkem C, Ejuh GW, Tchangnwa Nya F, Yossa Kamsi RA, Ndjaka JMB (2019) Theoretical study of optoelectronic properties of the molecule 2-cyano-3-[4-(diphenylamino) phenyl] acrylic acid. J. Iranian Chem. Soc. https://doi.org/10.1007/s13738-019-01790 $-4$

26. Veved A, Ejuh GW, Djongyang N (2020) Study of the optoelectronic and piezoelectric properties of $\mathrm{ZrO}_{2}$ doped PVDF from quantum chemistry calculations. Chin. J. Phys. 63:213

27. Pérez-Jiménez AJ, Sancho-Garca JC (2009) Assessment of double-hybrid energy functionals for $\pi$-conjugated systems. J Am Chem Soc 131:14857

28. Delgado MCR, Pigg KR, Da Silva Filho D A, Gruhn NE, Sakamoto Y, Suzuki T, Osuna RM, Casado J, Hernandez V, Navarrete JTL, Martinelli NG, Cornil J, Sanchez-Carrera RS, Coropceanu V, Bredas J-L (2009) Impact of peruorination on the charge-transport parameters of oligoacene crystals. J Am Chem Soc 131(4):1502

29. Tang MT, Bao Z (2011) Halogenated materials as organic semiconductors. Chem Mater 23(3):446

30. Cardia R, Malloci G, Serra G, Bosin A, Cappellini G (2016) Electronic and optical properties of functionalized polyaromatic hydrocarbons: a computational investigation on perfluorinated circumacenes. Proc. SPIE 9895 Org Photon II. https:// doi.org/10.1117/12.2229744

31. Sancho-García JC, Pérez-Jiménez AJ (2014) Theoretical study of stability and charge-transport properties of coronene molecule and some of its halogenated derivatives: a path to ambipolar organic-based materials. J. Chem. Phys. 141:134708

32. Morisset S, Rougeau N, Teillet-Billy D (2017) Influence of a graphene surface on the first steps of the hydrogenation of a coronene molecule. Chem Phys Lett 679:225

33. Kowalzik $P$, Rathgeber $S$, Karthauser $S$, Waser R, Schnaebele N, Raimundo J-M, Gingras M (2012) Columnar self-assembly of a 3D-persulfurated coronene asterisk. The dominant role of aryl-sulfur bonds. New J Chem 36:477

34. Ito S, Wehmeier M, Brand JD, Kubel C, Epsch R, Rabe JP, Mullen $\mathrm{K}$ (2000) Synthesis and self-asembly of functionalized hexaperi-hexabenzocoronenes. Chem Eur J 6(23):4327

35. Wang C, Dong H, Hu W, Liu Y, Zhu D (2012) Semiconducting $\pi$-conjugated systems in field-effect transistors: a material odyssey of organic electronics. Chem Rev 112:2208

36. Kang MJ, Doi I, Mori H, Miyazaki E, Takimiya K, Ikeda M, Kuwabara H (2011) Alkylated dinaphtho[2,3-b:2', 3'-f]thieno[3,2-b] thiophenes (Cn-DNTTs): organic semiconductors for high performance thin-film transistors. Adv Mater 23:1222

37. Fichou DJ (2000) Structural order in conjugated oligothiophenes and its implications optoelectronic in devices. Mater. Chem. 10:571

38. Allard S, Forster M, Souharce B, Thiem H, Scherf U (2008) Organic semiconductors for solution-processable field-effect transistors (OFETs). Angew Chem Int Ed 47:4070

39. Sanyal S, Manna AK, Pati KS (2013) Effect of imide functionalization on the electronic, optical, and charge transport properties of coronene: a theoretical study. J Phys Chem C 117(2):825

40. Kosugi T, Miyake T, Ishibashi S, Arita R, Aoki H (2011) Ab initio electronic structure of solid coronene: differences from and commonalities to picene. Phys. Rev. B 84:020507

41. Roth F, Bauer J, Mahns B, Buchner B, Knupfer M (2012) Electronic structure of undoped and potassium-doped coronene investigated by electron energy-loss spectroscopy. Phys. Rev. B 85:014513

42. Fedorov I, Zhuravlev Y, Berveno V (2012) Properties of crystalline coronene: dispersion forces leading to a larger van der Waals radius for carbon. Phys Status Solidi B 249:1438

43. Zhang M, Guo X, Ma W, Ade H, Hou J (2015) A large-bandgap conjugated polymer for versatile photovoltaic applications with high performance. J Adv Mater 27:4655

44. Zheng Z, Awartani OM, Gautam B, Liu D, Qin Y, Li W, Bataller A, Gundogdu K, Ade H, Hou J (2017) Efficient charge transfer 
and fine-tuned energy level alignment in a THF-processed fullerene-free organic solar cell with $11.3 \%$ efficiency. J Adv Mater 29(5):1604241

45. Dai S, Zhao F, Zhang Q, Lau TK, Li T, Liu K, Ling Q, Wang W, Lu X, You W, Zhan X (2017) Fused nonacyclic electron acceptors for efficient polymer solar cells. J Am Chem Soc 139(3):1336

46. Fan Q, Su W, Wang Y, Guo B, Jiang Y, Guo X, Liu F, Russell TP, Zhang M, Li Y (2018) Synergistic effect of fluorination on both donor and acceptor materials for high performance nonfullerene polymer solar cells with $13.5 \%$ efficiency. Sci China Chem. 61:531

47. Kan B, Feng $\mathrm{H}$, Yao H, Chang M, Wan X, Li C, Hou J, Chen Y (2018) A chlorinated low-bandgap small-molecule acceptor for organic solar cells with $14.1 \%$ efficiency and low energy loss. Sci China Chem. 61:1307

48. Frisch MJ, Trucks GW, Schlegel HB, Scuseria GE, Robb MA, Cheeseman JR, Scalmani G, Barone V, Mennucci B, Petersson GA, Nakatsuji H, Caricato M, Li X, Hratchian HP, Izmaylov AF, Bloino J, Zheng G, Sonnenberg JL, Hada M, Ehara M, Toyota K, Fukuda R, Hasegawa J, Ishida M, Nakajima T, Honda Y, Kitao O, Nakai $\mathrm{H}$, Vreven T, Montgomery JA Jr, Peralta JE, Ogliaro F, Bearpark MJ, Heyd J, Brothers EN, Kudin KN, Staroverov VN, Kobayashi R, Normand J, Raghavachari K, Rendell AP, Burant JC, lyengar SS, Tomasi J, Cossi M, Rega N, Millam NJ, Klene M, Knox JE, Cross JB, Bakken V, Adamo C, Jaramillo J, Gomperts R, Stratmann KM, Yazyev O, Austin AJ, Cammi R, Pomelli C, Ochterski JW, Martin RL, Morokuma K, Zakrzewski VG, Voth GA, Salvador P, Dannenberg JJ, Dapprich J, Daniels AD, Farkas O, Foresman JB, Ortiz JV, Cioslowski J, Fox DJ (2010) Gaussian 09, revision C.01. Gaussian Inc., Wallingford

49. Yossa Kamsi RA, Ejuh GW, TadjouteuAssatse Y, Tchoffo F, Ndjaka JMB (2019) Computational study of reactivity and solubility Rubescin $D$ and $E$ in gas phase and in solvent media using HatreFock and DFT method. Chin. J. Phys. 60:1

50. Malloci G, Cappellini G, Mulas G, Satta G (2004) Quasi-particle effects and optical absorption in small fullerene-like gap clusters. Phys. Rev. B 70:205429

51. Fonkem C, Ejuh GW, Tchangnwa Nya F, Yossa Kamsi RA, Tadjouteu Assatse Y, Ndjaka JMB (2020) A Density Functional Theory (DFT) study of the doping effect on 2-cyano-3- [4 (diphenylamino) phenyl] acrylic acid. Chin. J. Phys. 63:207

52. Geerlings P, De Proft F, Langenaeker W (2003) Conceptual density functional theory. Chem Rev 103(5):1793

53. Yossa Kamsi RA, Ejuh GW, Nkounga P, Ndjaka JMB (2020) Study of the molecular structure, electronic and chemical properties of Rubescin D molecule. Chin. J. Phys. 60:104

54. Pearson RG (1988) Absolute electronegativity and hardness: application to inorganic chemistry. Inorg Chem 27:7

55. Henríquez-Román JH, Padilla-Campos L, Páez MA, Zagal JH, María Rubio A, Rangel CM, Costamagna J, Cárdenas-Jirón GJ (2005) The influence of aniline and its derivatives on the corrosion behaviour of copper in acid solution: a theoretical approach. Mol. Struct. 757:1

56. Reis H, Papadopoulos MG, Calaminici P, Jug J, Koster AM (2000) Calculation of macroscopic linear and nonlinear optical susceptibilities for the naphthalene, anthracene and meta-nitroaniline crystals. J. Chem. Phys. 261:359

57. Sajan D, Joe H, Jayakumar VS, Zaleski J (2006) Structural and electronic contributions to hyperpolarizability in methyl p-hydroxy benzoate. J Mol Struct 785:43
58. Nagalakshmi R, Krishnarkumar V, Hagemann $\mathrm{H}$, Muthunatesan $S$ (2011) Polarized Raman and hyperpolarizability studies of Hydroxyethylammonium (I) tartrate monohydrate for quadratic nonlinear optics. J Mol Struct 988:17

59. Alyar H (2013) A review on nonlinear optical properties of donor-acceptor derivatives of naphthalene and azanaphthalene. Rev. Adv. Mater. Sci. 34:79

60. Wu K, Snijders JG, Lin C (2002) Reinvestigation of hydrogen bond effects on the polarizability and hyperpolarizability of urea molecular clusters. J. Phys. Chem. B 106(35):8954

61. Champagne B, Spassova M (2009) Theoretical investigation on the polarizability and second hyperpolarizability of polysilole. Chem Phys Lett 471:111

62. Wang C, Yuan Y, Tian X, Sun J, Yuan J (2016) The effects of exact exchange of density functionals on the evaluation of second hyperpolarizabilities of streptocyanines using sum-over-states method. Comput. Theor. Chem. 1085:40

63. Ejuh GW, Ottou Abe MT, Ghislain T, Ndjaka JMB (2018) Ab Initio and DFT studies on the donor-acceptor molecules 1,2,3-trihydroxy-9,10-anthraquinone; 1-(methylamino) anthraquinone; 2-phenyl quinoxaline and 2-(4-aminophenyl) quinoxaline. Mater. Focus 7(1):37

64. Clar E, Schmidt W (1976) Correlations between photoelectron and phosphorescence spectra of polycyclic hydrocarbons. Tetrahedron 32(21):2563

65. Boschi R, Schmidt W (1972) Photoelectron spectra of polycyclic aromatic hydrocarbons. Tetrahedron Lett 13(25):2577

66. Kuroda $\mathrm{H}$ (1964) Ionization potentials of polycyclic aromatic hydrocarbons. Nature 201:1214

67. Clar E, Robertson JM, Schlogl R, Schmidt W (1981) Photoelectron spectra of polynuclear aromatics. Applications to structural elucidation: "circumanthracene". J Am Chem Soc 103(6):1320

68. Schröder D, Loos J, Schwarz H, Thissen R, Preda DV, Scott LT, Caraiman D, Frach MV, Böhme DK (2001) Single and double ionization of corannulene and coronene. Helv Chim Acta 84:1625

69. Duncan MA, Knight AM, Negishi Y, Nagao S, Nakamura Y, Kato A, Nakajima A, Kaya K (1999) Production of jet-cooled coronene and coronene cluster anions and their study with photoelectron spectroscopy. Chem Phys Lett 309:49

70. Kandalam AK, Kiran B, Jena P, Li X, Grubisic A, Bowen KH (2007) Ground state structures and photoelectron spectroscopy of [Com(coronene)](-) complexes. J. Chem. Phys. 126:084306

71. Chen-Jen Y, Jenekhe AS (1995) conjugated aromatic polyimines. 2. Synthesis, structure, and properties of new aromatic polyazomethines. Macromol. 28:1180

72. Kosugi T, Miyake T, Ishibashi S, Arita R, Aoki H (2011) Electronic structure of solid coronene: differences and commonalities to picene. Cond-Mat. Sup-Con, (2011), arXiv:1105.0248(2)

73. Chang-Guo Z, Nichols JA, Dixon DA (2003) lonization potential, electron affinity, electronegativity, hardness, and electron excitation energy: molecular properties from density functional theory orbital energies. J Phys Chem A 107(20):4184

Publisher's Note Springer Nature remains neutral with regard to jurisdictional claims in published maps and institutional affiliations. 